\title{
PENGARUH RETAIL MARKETING MIX TERHADAP UNPLANNING PURCHASE DICISIONS PADA BISNIS MINIMART DI DESA UBUD KABUPATEN GIANYAR
}

\author{
Ni Luh Ketut Ayu Sudha Sucandrawati ${ }^{1}$ \\ Ni Luh Parmi Widiasih²
}

\author{
Program Studi Managemen, Fakultas Ekonomi, \\ Universitas Mahendradatta \\ Jl.Ken Arok No.12, Peguyangan Denpasar Utara, Bali 80115 \\ Email : ayusucandra89@gmail.com
}

\begin{abstract}
Abstrak - Perkembanganpasar retail modern saat ini membuat pembelian tidak terencana atau unplaning purchase dicisionssemakin meningkat di masyarakat. Penelitian ini bertujuan untuk menguji pengaruh retail marketing mix terhadap unplanned purchase desicions pada toko Minimart di Desa Ubud Kabupaten Gianyar Bali dengan menggunakan sampel sebanyak 86 orang melalui metode slovin. Teknik analisis yang digunakan adalah regresi linear berganda.

Hasil analisis membuktikan bahwa retail marketing mix yang terdiri dari lokasi, merchandise, pricing, promosi, atmosfer gerai dan retail service berpengaruh positif dan signifikan secara parsial terhadap unplanned purchase desicions pada toko Minimart di Desa Ubud Kabupaten Gianyar Bali.Retail marketing mix yang terdiri dari lokasi, merchandise, pricing, promosi, atmosfer gerai dan retail service berpengaruh positif dan signifikan secara simultan terhadap unplaning purchase dicisionspada toko Minimart di Desa Ubud Kabupaten Gianyar Bali.

Saran yang dapat direkomendasikan kepada pihak manajemen Minimart di Desa Ubud Kabupaten Gianyar Bali memperhatikan hal-hal yang menyangkut dengan retail marketing mix diantaranya adalah lokasi, merchandise, pricing, promosi, atmosfer gerai dan retail service yang lebih baik dalam menarik minat pengunjung untuk melakukan unplaning purchase dicisionsdi Minimart di Desa Ubud Kabupaten Gianyar Bali.Lokasi yang disediakan untuk pengunjung dengan mudah terjangkau dan parkir yang luas. Merchandise yang disediakan agar lebih beragam sesuai dengan kebutuhan konsumen. Harga yang ditetapkan agar melihat persaingan pasar sehingga konsumen bersedia berbelanja di Minimart. Memberikan periklanan dan promosi yang menarik guna mempengaruhi pembelian konsumen. Atmosfer dalam gerai diharapkan Minimart di Desa Ubud Kabupaten Gianyar Bali dapat memberikan ruang gerak yang lebih luas untuk pengunjung. Penerapan service yang maksimal dalam pelayanan, kemudahan pembayaran sehingga menarik unplaning purchase dicisionsdi Minimart di Desa Ubud Kabupaten Gianyar Bali.
\end{abstract}

Kata Kunci: Marketing Mix , Pembelian tidak terencana 
Abstract - The development of modern retail market today makes unplanned purchases or unplaning purchase dicisionsincreasing in society. This study aims to examine the effect of retail marketing mix on unplanned purchase desicions at Minimart shop in Ubud Village of Gianyar Bali Regency using sample of 86 people through slovin method. The analysis technique used is multiple linear regression analysis.

The results of the analysis prove that retail marketing mix consisting of location, merchandise, pricing, promotion, atmosphere of outlets and retail service have a positive and partially significant effect on unplaning purchase dicisionsat Minimart shop in Ubud Village of Gianyar Bali Regency. Retail marketing mix consisting of location, merchandise, pricing, promotion, atmosphere of outlet and retail service have positive and significant influence simultaneously to unplaning purchase dicisionsat Minimart shop in Ubud Village of Gianyar Bali Regency.

Suggestions that can be recommended to the management of Minimart in Ubud Village Gianyar regency of Bali to pay attention to matters related to retail marketing mix such as location, merchandise, pricing, promotion, atmosphere of outlets and retail service better in attracting visitors to do unplaning purchase dicisionsat Minimart in Ubud Village, Gianyar Regency, Bali. Locations provided for easily accessible visitors and ample parking. Merchandise provided to be more diverse in accordance with the needs of consumers. The price set to see the market competition so that consumers are willing to shop at Minimart. Providing attractive advertising and promotions to influence consumer purchases. The atmosphere in the booth is expected Minimart in Ubud Village Gianyar regency of Bali can provide wider space for visitors. Implementation of the maximum service in the service, ease of payment so as to attract unplaning purchase dicisionsin Minimart in Ubud Village Gianyar regency Bali.

Keywords : Marketing Mix, Unplanning Purchase Decision

\section{PENDAHULUAN}

Dewasa ini perkembangan pasar retail modern di tanah air, tampak cukup pesat.Hampir di setiap Ibukota Propinsi dan kota-kota besar lainnya bermunculan pasar retail modern dengan berbagai fasilitas dan pelayanan yang semakin lengkap. Pasar retail modern sebagai ujung tombak pemasaran akan terus bertambah, dan yang sudah ada terus dikembangkan hingga menjadi superstore yaitu pasar swalayan yang menyediakan kebutuhan masyarakat yang selengkaplengkapnya (Abdul et al., 2013). Munculnya berbagai macam retail store seperti salah satunya Minimart menimbulkan persaingan yang ketat antara perusahaan sejenis dalam melaksanakan aktivitasnya. Dari situasi tersebut para pemasar harus mencari cara agar menarik perhatian pengunjung untuk memasuki swalayannya dan melakukan pembelian terhadap produk-produk yang ada di Minimart tersebut.

Berbelanja merupakan kegiatan menyenangkan bagi sebagian orang, karena belanja bukan hanya sebagai aktivitas rutin untuk memenuhi keinginan dan kebutuhan konsumen, tetapi seringkali kegiatan belanja menjadi sarana rekreasi 
dan hiburan (Erina, 2015).Hendro et al. (2013) mengatakan kebutuhan dan keinginan manusia selalu menjadi hal yang utama bagi para peritel.Pengusaha dapat menggunakan hal ini sebagai prospek dalam bisnis, sesuai dengan adanya permintaan dan penawaran.Jumlah populasi manusia yang terus bertambah membuat tingkat kebutuhan dan keinginan manusia juga terus bertambah (Hartono, 2011).Retailer harus berusaha menawarkan berbagai rangsangan yang mampu menarik minat konsumen untuk melakukan pembelian.

Kotler (2012:216) menyatakan pembelian tidak terencana atau unplaning purchase dicisions merupakan kecenderungan konsumen untuk membeli suatu merek atau mengambil tindakan yang berhubungan dengan pembelian yang diukur dengan tingkat pembelian yang tidak terencana.KotlerandArmstrong (2012:53) menyatakan konsumen pun semakin jeli dan kritis dalam memilih produk atau barang yang akan dibeli. Konsumen akan mudah terpancing untuk melakukan unplaning purchase dicisions dengan adanya sarana dan suasana yang mendukung, hal ini mengindikasikan bahwa fenomena unplaning purchase dicisions selalu terjadi pada saat konsumen berbelanja.

Retail marketing mix dapat menarik minat pembelian konsumen yang pada awalnya tidak berniat melakukan pembelian pada suatu ritel karena adanya retail marketing mix maka konsumen akan tertarik dan pada akhirnya melakukan keputusan pembelian (Kotler, 2012:225).Rangsangan didalam supermarket yang meliputi lokasi, merchandise, pricing, promosi dan pengiklanan, atmosfer dalam gerai, dan retail service memberikan informasi penting yang mendorong konsumen untuk membentuk penilaian tentang harga, produk dan jasa didalam supermarket (Michael et al., 2016).

Meningkatnya persaingan dan tuntutan pelanggan memaksa retailer untuk fokus pada pelaksanaan peningkatan yang berkelanjutan terhadap pelayanan yang diberikan.Minimart adalah supermarket yang menawarkan berbagai macam barang kebutuhan sehari-hari. Minimart merupakan salah satu supermarket yang menghadapi ketatnya persaingan bisnis retailer pada saat ini. Ubud sebagai wilayah pariwisata di Bali muncul berbagai supermarket berskala kecil yang lebih berorientasi dekat dengan pelanggan.Konsep ini membuat orang merasa segan bepergian jauh untuk memenuhi kebutuhan sehari-hari,dengan harga yang relatif lebih murah.Munculnya pesaing-pesaing ini sangat menyulitkan posisi Minimart.Masalah penurunan penjualan juga disebabkan oleh penurunan jumlah pelanggan yang ditunjukkan pada Tabel 1.1 berikut 
Tabel 1.1 Jumlah Pelanggan Minimart Tahun 2013-2017

\begin{tabular}{|c|c|c|c|}
\hline No. & Tahun & Jumlah Pelanggan Minimart (Orang) & Persentase (\%) \\
\hline 1 & 2013 & 7.324 & - \\
\hline 2 & 2014 & 6.894 & $(0,05)$ \\
\hline 3 & 2015 & 6.256 & $(0,09)$ \\
\hline 4 & 2016 & 6.155 & $(0,02)$ \\
\hline 5 & 2017 & 6.237 & 0,02 \\
\hline
\end{tabular}

Sumber: Minimart, data primer diolah, 2018

Tabel 1.1 menunjukkan jumlah pelanggan minimart di wilayah Ubud dari tahun 2013 sampai tahun 2017. Data menunjukkan bahwa pelanggan di Minimart mengalami penurunan dari tahun ke tahun, penurunan tertinggi dari tahun 2014 ke tahun 216 dimana angka menunjukkan 6.894 orang menjadi 6.256 orang di tahun 2015. Berbelanja bertujuan untuk memenuhi keinginan dan kebutuhan konsumennya dalam berbelanja, seperti harga yang terjangkau, produk-produk pilihan, kebersihan, dan kualitas layanan sehingga konsumen betah dan melakukan pembelian berulang-ulang.Industri retail penting untuk dipelajari yaitu; pertama, implikasi retailing dalam perekonomian global, penjualan retailing dan daya serap tenaga kerjanya menjadi kunci perekonomian global.Kedua, fungsi retail dalam rantai distribusi, retail berfungsi menjadi penghubung antara final consumer, dengan manufacture dan whole saler.Ketiga, hubungan antara pengecer dengan pelanggan (Oei, 2015).Pelayanan yang baik dan memuaskan terhadap pelanggan merupakan misi utama bagi sebuah supermarket dimana kepuasan pelanggan menjadi sorotan utama bagi banyak perusahaan-perusahaan dalam memutuskan strategi untuk memenangkan persaingan.
Permasalahan pada perusahaan di bidang retailer saat ini adalah kurangnya memperhatikan atmosfer dalam gerai kebersihan dan suasana toko yang sering kotor baik di dalam maupun di luar toko.Keadaan lokasi yang tidak mendukung dengan ketersediaan tempat parkir yang minim. Minimnya merchandise yang dijual dalam toko seperti variasi merk dan persediaan produk. Periklanan dan promosi yang dilakukan cenderung monoton tidak ada perubahan dari segi penawaran dan layanan yang diberikan. Retail service yang kurang memahami keinginan konsumen seperti: jumlah pramuniaga yang kurang memadai, (2) pramuniaga yang kurang senantiasa melayani, (3) layanan transaksi yang kurang cepat seperti cara pembayaran yang mudah melalui e-banking atau m-transfer (Rafinko, 2017).

Kondisi persaingan retailer yang di ikuti oleh Minimart di wilayah Ubud bertujuan untuk memenuhi keinginan dan kebutuhan konsumennya dalam berbelanja, seperti harga yang terjangkau, produk-produk pilihan, kebersihan, dan kualitas layanan sehingga konsumen betah dan melakukan pembelian berulang-ulang. Industri retail penting untuk dipelajari yaitu; pertama, implikasi retailing dalam perekonomian global, penjualan retailing dan daya serap tenaga kerjanya menjadi kunci 
perekonomian global.Kedua, fungsi retail dalam rantai distribusi, retail berfungsi menjadi penghubung antara final consumer, dengan manufacture dan whole saler.Ketiga, hubungan antara pengecer dengan pelanggan (Urfia, 2016).Pelayanan yang baik dan memuaskan terhadap pelanggan merupakan misi utama bagi sebuah supermarket dimana kepuasan pelanggan menjadi sorotan utama bagi banyak perusahaan-perusahaan dalam memutuskan strategi untuk memenangkan persaingan (Wahju, 2016).

\section{Perumusan Masalah}

Berdasarkan latar belakang, maka dapat dirumuskan permasalahan sebagai berikut.

1. Apakah lokasi, merchandise, pricing, promosi, atmosfir dalam gerai berpengaruh terhadap unplaning purchase dicisions konsumen di Minimart Desa Ubud Kabupaten Gianyar Provinsi Bali?

2. Apakah, retail service berpengaruh secara simultan terhadap unplaning purchase dicisionsconsumer di Minimart Desa Ubud Kabupaten Gianyar Provinsi Bali?

\section{Tujuan Penelitian}

Untuk menganalisis pengaruh retail service terhadap unplaning purchase dicisions konsumen di Minimart Desa Ubud Kabupaten Gianyar Provinsi Bali.

Untuk menganalisis pengaruh lokasi, merchandise, pricing, periklanan dan promosi, atmosfer dalam gerai, retail service secara simultan terhadap unplaning purchase dicisions konsumen di Minimart Desa Ubud Kabupaten Gianyar Provinsi Bali.

\section{Kegunaan Penelitian}

a. Penelitian ini diharapkan dapat menjelaskan pemahaman serta memperluas pengetahuan dan wawasan dilingkungan akademis. Memberikan manfaat bagi pihakpihak yang berkepentingan khususnya mengenaipermasalahan unplaning purchase dicisions konsumen dan retail marketing mix.

b. Penelitian ini dapat dipakai untuk menambah referensi bacaan perpustakaan di Universitas sehingga dapat dipergunakan sebagai pedoman untuk penelitian lebih lanjut.

c. Penelitian ini diharapkan dapat digunakan sebagai bahan pertimbangan bagi pihak manajemen Minimart dalam mempertahankan konsumen dan meningkatkan unplaning purchase dicisions konsumen. 
1. Manajemen Pemasaran

Manajemen pemasaran terjadi bila setidaknya satu pihak dalam pertukaran potensial memikirkan sasaran dan cara mendapatkan tanggapan yang dia kehendaki dari pihak lain. Kotler dan Keller (2009:87) mengemukakan bahwa sasaran pemasaran perlu diperhitungkan dalam rencana bisnis keseluruhan dari suatu perusahaan. Ketika menetapkan prioritas, perusahaan harus menentukan bukan hanya langkah apa saja yang dibutuhkan tetapi juga bagaimana langkah itu akan dipandang oleh mitra, pendukung dan penerima manfaat yang terkait dengan rencana pasar, baik di dalam maupun di luar perusahaan.

\section{Perilaku Konsumen}

Schiffman \& Kanuk, (2017:5) menjelaskan perilaku konsumen adalah studi tentang perilaku yang ditujukan oleh konsumen dalam mencari, membeli, menggunakan, mengevaluasi dan membuang produk dan jasa yang diharapkan akan memenuhi berbagai kebutuhannya. Perilaku konsumen sangat dipengaruhi oleh faktor-faktor yang ada diluar diri manusia (eksternal) dan faktorfaktor yang ada di dalam diri manusia (internal).Faktor eksternal yang utama adalah faktor kebudayaan dan sosial sedangkan faktor-faktor internal yang utama adalah faktor pribadi dan psikologis.

Mempermudah dalam mempelajari perilaku konsumen digunakan berbagai macam model perilaku konsumen yang merupakan kerangka kerja yang disederhanakan untuk menggambarkan aktifitas konsumen. Salah satu model perilaku konsumen menurut Kotler, (2012: 203) disajikan pada Gambar1 
.Gambar1 Model Perilaku Pembeli

\begin{tabular}{|c|c|c|c|c|}
\hline $\begin{array}{c}\text { Rangsangan } \\
\text { Pemasaran }\end{array}$ & $\begin{array}{c}\text { Rangsangan } \\
\text { Lain }\end{array}$ & $\begin{array}{l}\text { Ciri-ciri } \\
\text { Pembeli }\end{array}$ & Proses & $\begin{array}{l}\text { Keputusan } \\
\text { Pembelian }\end{array}$ \\
\hline $\begin{array}{l}\text { Produk } \\
\text { Harga } \\
\text { Saluran } \\
\text { Pemasaran } \\
\text { Promosi }\end{array}$ & $\begin{array}{l}\text { Ekonomi } \\
\text { Teknologi } \\
\text { Politik } \\
\text { Budaya }\end{array}$ & $\begin{array}{l}\text { Budaya } \\
\text { Sosial } \\
\text { Pribadi } \\
\text { Psikologi }\end{array}$ & $\begin{array}{l}\text { Pemahaman } \\
\text { masalah } \\
\text { Pencarian } \\
\text { Informasi } \\
\text { Pemilihan } \\
\text { Alternatif } \\
\text { Keputusan } \\
\text { Pembelian } \\
\text { Perilaku } \\
\text { Pasca } \\
\text { Pembelian }\end{array}$ & $\begin{array}{l}\text { Pemilihan } \\
\text { Produk } \\
\text { Merek } \\
\text { Pemilihan } \\
\text { Saluran } \\
\text { Pembelian } \\
\text { Penentuan } \\
\text { waktu } \\
\text { Pembelian } \\
\text { Jumlah } \\
\text { Pembelian }\end{array}$ \\
\hline
\end{tabular}

Sumber: Kotler, (2012:203)

\section{METODE}

\begin{abstract}
Penelitian ini dilakukan dengan menggunakan metode asosiatif.Penelitian asosiatif adalah penelitian yang bertujuan untuk mengetahui hubungan antar dua variabel atau lebih (Sugiyono, 2013:56).Penggunaan metode ini untuk menganalisis pengaruh persaingan antara toko retail modern Minimart terhadap unplaning purchase dicisions dalam perspektif retail marketing mix (Studi kasus pada toko Minimart di Desa Ubud Provinsi Bali).
\end{abstract}

\section{Rumus Slovin (Sugiyono,} 2013:124) yaitu:

$$
\begin{aligned}
& \mathrm{n}=\frac{\mathrm{N}}{1+\mathrm{Ne}^{2}} \\
& \text { dimana: } \\
& \mathrm{n}=\text { Ukuran sampel } \\
& \mathrm{N}=\text { Ukuran populasi }
\end{aligned}
$$

\section{Populasi dan Metode Penentuan Sampel}

Menurut Sugiyono (2013:65), sampel adalah sebagian dari jumlah dan karakteristik yang dimiliki oleh populasi tersebut. Maka sampel dalam penelitian ini adalah konsumen yang memenuhi kriteria tertentu yang sesuai dengan penelitian unplaning purchase dicisions di Minimart.

Populasi dari penelitian ini adalah konsumen minimart tahun 2017 yang berjumlah 6.237 orang. Menentukan ukuran sampel yang ada peneliti menggunakan rumus Slovin
$\mathrm{e}=$ Persen kelonggaran ketidaktelitian karena kesalahan pengambilan.

Sampel yang masih dapat ditolerir atau diinginkan. Batasbatas kesalahan yang dapat digunakan ialah mulai dari 1-10\%. 
Populasi yang digunakan dalam penelitian ini ialah 6.237orang, dengan menggunakan batas kesalahan sebesar $10 \%$ sehingga dapat dihitung sebagai berikut :

$$
\begin{aligned}
n & =\frac{6.237}{1+(6.237 \times 0.05)^{2}} \\
& =\frac{6.237}{1+6.237} \\
& =6.237 \\
& =86,1
\end{aligned}
$$

\section{Metode Pengumpulan Data}

Pengumpulan data dalam penelitian ini dilakukan dengan menggunakan metode Wawancara, Pustaka, Kuisioner dan Observasi. 1.

\section{Teknik Analisis Data}

Analisis Deskriptif dana Analisis Regresi Linier Berganda

\section{HASIL DAN PEMBAHASAN}

Deskripsi Objek Penelitian

\section{Sejarah singkat Minimart (PT. Global} Retailindo Pratama)

Mini Mart adalah sebuah brand minimarket yang memiliki konsep convenience store yang dimiliki oleh PT.Global Retailindo Pratama yang berkantor di jalan nyang-nyang sari tuban. Toko kelontong atau mini market (bahasa Inggris: convenience store) adalah suatu toko kecil yang umumnya mudah diakses umum atau bersifat lokal. Toko semacam ini umumnya berlokasi di jalan yang ramai, stasiun pengisian bahan bakar (SPBU), atau stasiun kereta api,toko kelontong sering ditemukan di lokasi perumahan padat di perkotaan.

PT. Global Retailindo Pratama memiliki beberapa toko yang tersebar di seluruh bali dan akan terus bertambah seiring berjalannya waktu dan
Besarnya jumlah sampel yang didapat ialah 86 orang. Sampel yang ada akan peneliti berdasarkan metode Proportionate Random Samplingkarena anggota populasi bersifat homogen sehingga dapat mewakili seluruh populasi yang ada. Adapun pertimbangan yang digunakan dalam pengambilan sampel adalah sebagai berikut:

a) Responden yang berusia minimal 17 tahun.

b) Responden yang mengetahui Minimart.

c) Responden yang sudah pernah berkunjung ke di Minimart.

Analisis deskriptif dalam penelitian ini digunakan untuk mendeskripsikan objek yang diteliti melalui data sampel atau populasi sebagaimana adanya. Analisis Regresi Berganda adalah data yang dikumpulkan untuk mengetahui ketegantungan suatu variabel terikat dengan satu atau lebih variabel bebas.

perkembangan perusahaan ini.di daerah Ubud ada 12 toko dimana tempat saya bekerja sekaligus tempat saya melakukan penelitianVisi dan Misi perusahaan adalah menjadi jaringan ritel modern yang mengedepankan kepuasan pelanggan,inovatif dan mampu bersaing secara global. Budaya kerja yang di miliki perusahaan adalah FOKUS yg memiliki arti sebagai berikut: Fokus pada pelanggan, Optomis, Kreatif dan inovatif, Usaha yang berkesinambungan, Semangat, integritas dan handal.

\section{Struktur Organisasi}

Struktur Organisasi adalah kerangka dan susunan perwujudan pola tetap hubungan-hubungan diantara fungsifungsi, bagian-bagian atau posisi, maupun orang-orang yang menunjukkan tugas, wewenag dan tanggung jawab 
yang berbeda-beda dalam suatu dimana aliran wewenang, tanggung organisasi (Handoko, 2006:169). jawab, dan pelimpahan kekuasaan dari Struktur Organisasi yang digunakan oleh atas ke bawah Gambar 2.2.

PT. Global Retailindo Pratama yaitu

Struktur Organisasi bentuk Piramid

Gambar2

Struktur OrganisasiPT. Global Retailindo Pratama

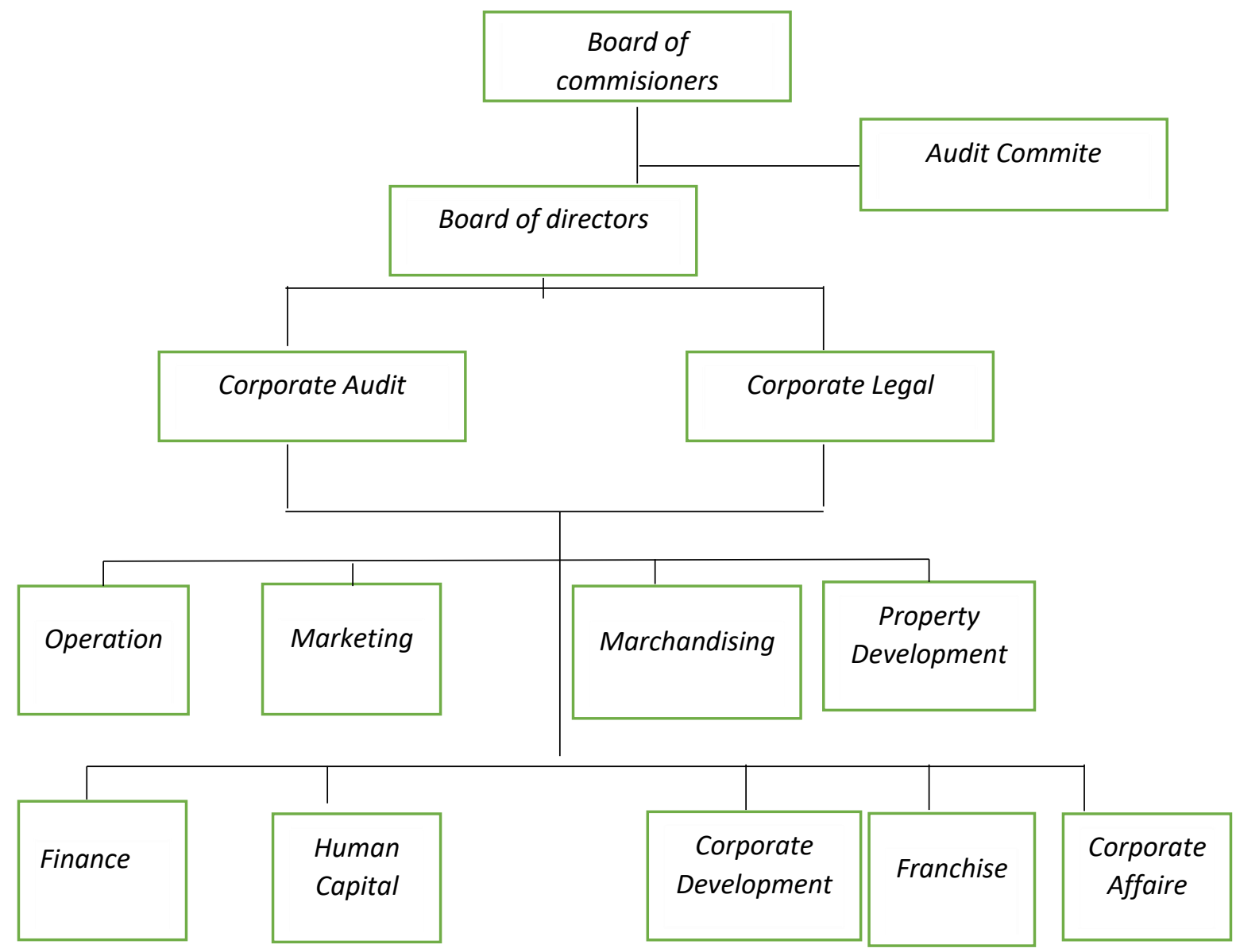

Sumber : PT. Global Retailindo Pratama, 2018

Ni Luh Ketut Ayu Sudha Sucandrawati 


\section{Karakteristik Responden}

Deskripsi

karakteristik

responden adalah menguraikan atau memberikan gambaran mengenai identitas responden dalam penelitian ini, sebab dengan menguraikan identitas responden yang menjadi sampel dalam penelitian ini maka akan dapat diketahui sejauh

Tabel .3

mana identitas responden dalam penelitian ini. Oleh karena itulah deskripsi identitas responden dalam penelitian ini dapat dikelompokkan menjadi beberapa kelompok yaitu: jenis kelamin, usia, pekerjaan dan penghasilan dapat dilihat pada Tabel 2.3

\section{Karakteristik Responden}

\begin{tabular}{|c|c|c|c|c|}
\hline No & Variabel & Klasifikasi & $\begin{array}{l}\text { Jumlah } \\
\text { (orang) }\end{array}$ & Persentase \\
\hline \multirow{3}{*}{1} & \multirow{2}{*}{$\begin{array}{c}\text { Jenis } \\
\text { Kelamin }\end{array}$} & Laki-Laki & 48 & 55,8 \\
\hline & & Perempuan & 38 & 44,2 \\
\hline & \multicolumn{2}{|r|}{ Jumlah } & 86 & 100 \\
\hline \multirow{5}{*}{2} & \multirow{4}{*}{ Umur } & 17-25 tahun & 38 & 44,2 \\
\hline & & 26-35 tahun & 23 & 26,7 \\
\hline & & 36-45 tahun & 11 & 12,7 \\
\hline & \multirow{2}{*}{\multicolumn{2}{|c|}{$\frac{>45 \text { tahun }}{\text { Jumlah }}$}} & 14 & 16,3 \\
\hline & & & 86 & 100 \\
\hline \multirow{5}{*}{4} & \multirow{4}{*}{ Pekerjaan } & Pelajar & 22 & 25,5 \\
\hline & & PNS & 32 & 32,2 \\
\hline & & Karyawan & 18 & 20,9 \\
\hline & & Wiraswasta & 14 & 16,3 \\
\hline & \multicolumn{2}{|r|}{$\frac{\text { Wiraswasta }}{\text { Jumlah }}$} & 86 & 100 \\
\hline \multirow{5}{*}{5} & \multirow{4}{*}{ Penghasilan } & $\leq$ Rp. 500.000,-- & 22 & 25,5 \\
\hline & & $\begin{array}{c}\text { >Rp. } 500.000,- \text { sd Rp. } \\
1.000 .000,-\end{array}$ & 32 & 32,2 \\
\hline & & $\begin{array}{l}\text { >Rp. } 1.000 .000,- \text { sd Rp. } \\
2.000 .000,-\end{array}$ & 18 & 20,9 \\
\hline & & $>$ Rp. 2.000.000,- keatas & 14 & 16,3 \\
\hline & & Jumlah & 86 & 100 \\
\hline
\end{tabular}

Sumber : Data Primer, diolah pada Tahun 2018

Tabel $\quad .3 \quad$ menunjukan karakteristik responden dapat dilihat berdasarkan pengelompokkan jenis kelamin, jenis kelamin laki-laki mendominasi dalam penelitian ini dengan persentase sebesar 55,8 persen, hal ini disebabkan karena produk yang dijual di Minimart kebanyakan dicari oleh kaum laki-laki. Berdasarkan umur responden di dominasi pada usia 17-25 tahun dengan persentase sebesar 44,2 persen. Persentase terkecil yaitu 12,7 persen dengan jumlah responden sebanyak 11 orang yang berumur 36-45 tahun. Hal ini berarti bahwa, masyarakat yang mendominasi berbelanja di Minimart rata-rata berumur 17-25 tahun di mana rentang usia ini termasuk rentak usia yang produktif dengan gaya hidup yang modern.

Berdasarkan pengelompokkan pekerjaan didominasi oleh PNS yaitu sebesar 32,2 persen dan persentase terkecil yaitu 16,3 persen dengan jumlah responden sebanyak 14 orang dengan 
pekerjaan wiraswasta.Hal ini dikarenakan dalam kategori menjadi pelanggan di Minimart, kebanyakan kalangan wiraswasta karena lokasi Minimart berada di daerah pariwisata.

Berdasarkan penghasilan didominasi oleh pelanggan yang berpenghasilan >Rp. 500.000,- sd Rp. 1.000.000,-dengan 32,2 persen dan persentase terkecil yaitu 16,3 persen

\section{Pembahasan Hasil Penelitian}

\section{Pengaruh LokasiTerhadap Unplaning} purchase dicisions Konsumen

Berdasarkan hasil analisis data diketahui bahwa lokasi berpengaruh signifikan positif terhadap unplaning purchase dicisions konsumen di Minimart di Desa Ubud Kabupaten Gianyar Bali. Hal ini mengandung arti bahwa semakin baik lokasi Minimart di Desa Ubud Kabupaten Gianyar Bali dengan menyediakan tempat parkir yang luas akan menarik minat konsumen untuk melakukanunplaning purchase dicisions.

\section{Pengaruh MerchendiseTerhadap} Unplaning purchase dicisions Konsumen

Berdasarkan hasil analisis data diketahui bahwa merchendise berpengaruh signifikan positif terhadap unplaning purchase dicisions konsumen di Minimart di Desa Ubud Kabupaten Gianyar Bali. Hal ini mengandung arti bahwa semakin beraneka ragam merchandise yang dijual diMinimart di Desa Ubud Kabupaten Gianyar Bali sesuai dengan kebutuhan konsumen saat ini akan menarik minat konsumen untuk melakukanunplaning purchase dicisions.

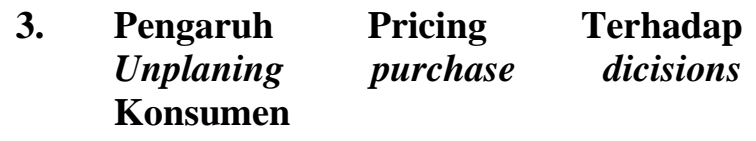

dengan jumlah responden sebanyak 14 orang yang berpenghasilan $>\mathrm{Rp}$. 2.000.000,- keatas. Hal ini dikarenakan dalam kategori menjadi pelanggan Minimart siapapun bias dilayani karena Minimart tidak memandang besar penghasilan seeorang dengan harga semua produk yang masih terjangkau dimasyarakat.
Berdasarkan hasil analisis data diketahui bahwa pricing berpengaruh signifikan positif terhadap unplaning purchase dicisions konsumen di Minimart di Desa Ubud Kabupaten Gianyar Bali. Hal ini mengandung arti bahwa Minimart di Desa Ubud Kabupaten Gianyar Bali harus mampu menetapkan harga terhadap beraneka ragam merchandise yang dijual sehingga mampu meningkatkan unplaning purchase dicisions konsumen

4. Pengaruh

Unplaning

PromosiTerhadap Konsumen

Berdasarkan hasil analisis data diketahui bahwa promosi berpengaruh signifikan positif terhadap unplaning purchase dicisions konsumen di Minimart di Desa Ubud Kabupaten Gianyar Bali. Hal ini mengandung arti bahwa semakin baik promosi yang dilakukan Minimart di Desa Ubud Kabupaten Gianyar Bali melalui media cetak, media elektronik dan media sosial akan mampu meningkatkan unplaning purchase dicisions konsumen dan memenangkan persaingan.

5. Pengaruh Atmosfer GeraiTerhadap Unplaning purchase dicisions Konsumen

Berdasarkan hasil analisis data diketahui bahwa atmosfer gerai berpengaruh 
signifikan positif terhadap unplaning purchase dicisions konsumen di Minimart di Desa Ubud Kabupaten Gianyar Bali. Hal ini mengandung arti bahwa Minimart di Desa Ubud Kabupaten Gianyar Bali membentuk dan mendekorasi setiap gerai atau tokonya dengan sedemikian rupa yang akan menarik minat konsumen untuk melakukanunplaning purchase dicisions.

\section{Pengaruh Retail Service Terhadap Unplaning purchase dicisions Konsumen}

Berdasarkan hasil analisis data diketahui bahwa retail service berpengaruh signifikan positif terhadap unplaning purchase dicisions konsumen di Minimart di Desa Ubud Kabupaten Gianyar Bali. Hal ini mengandung arti bahwa Minimart di Desa Ubud Kabupaten Gianyar Bali harus memberikan layanan baik dari karyawan, cara pembayaran yang cepat akan mampu meningkatkan unplaning purchase dicisions konsumen.

\section{KESIMPULAN DAN SARAN}

Simpulan

1) Lokasi berpengaruh positif dan signifikan secara parsial terhadap unplaning purchase dicisions konsumen di Minimart di Desa Ubud Kabupaten Gianyar Bali dengan nilai koefisien $\beta_{1}=$ 0,259 dan signifikansi $0,005<0,05$.

2) Merchendise berpengaruh positif dan signifikan secara parsial terhadap unplaning purchase dicisions konsumen di Minimart di Desa Ubud Kabupaten Gianyar Bali dengan nilai koefisien $\beta_{2}=$ 0.210 dan signifikansi $0,045<0,05$.

3) Pricing berpengaruh positif dan signifikan secara parsial terhadap unplaning purchase dicisions konsumen di Minimart di Desa Ubud Kabupaten Gianyar Bali dengan nilai koefisien $\beta_{3}=$ 0.218 dan signifikansi $0,020<0,05$.

4) Promosi berpengaruh positif dan signifikan secara parsial terhadap unplaning purchase dicisions konsumen di Minimart di Desa Ubud Kabupaten Gianyar Bali dengan nilai koefisien $\beta_{4}=$ 0.268 dan signifikansi $0,031<0,05$.

5) Atmosfer gerai berpengaruh positif dan signifikan secara parsial terhadap unplaning purchase dicisions konsumen di Minimart di Desa Ubud Kabupaten Gianyar Bali dengan nilai koef 0.213 dan signifikansi $0,032<1$ 72

6) Retail service berpengaruh pc signifikan secara parsial terhadap unplaning purchase dicisions konsumen di Minimart di Desa Ubud Kabupaten Gianyar Bali dengan nilai koefisien $\beta_{6}=$ 0.227 dan signifikansi $0,042<0,05$.

7) Lokasi, merchandise, pricing, promosi, atmosfer gerai dan retail service memiliki pengaruh positif dan signifikan secara simultan terhadap unplaning purchase dicisions konsumen di Minimart di Desa Ubud Kabupaten Gianyar Bali dengan nilai $F_{\text {hitung }}=76,460$ lebih besar daripada $\mathrm{F}_{\text {tabel }}=3,15$.

\section{Saran}

Berdasarkan simpulan di atas, maka adapun saran-saran yang dapat diberikan adalah sebagai berikut.

1. Disarankan kepada manajemen Minimart di Desa Ubud Kabupaten Gianyar Balimemperhatikan hal-hal yang menyangkut dalam pemberian pelayanan kepada konsumen yang menyangkut dengan retail marketing mix diantaranya adalah lokasi, merchandise, pricing, promosi, atmosfer gerai dan retail service 
yang lebih baik dalam menarik minat pengunjung untuk melakukan unplaning purchase dicisionsdi Minimart di Desa Ubud Kabupaten Gianyar Bali.

2. Diharapkan Minimart di Desa Ubud Kabupaten Gianyar Bali dapat menata kembali lokasi yang disediakan untuk pengunjung dengan mudah terjangkau dan parkir yang luas. Merchandise yang disediakan agar lebih beragam sesuai dengan kebutuhan konsumen saat ini untuk menarik minat konsumen. Harga yang ditetapkan agar melihat persaingan pasar sehingga konsumen bersedia berbelanja di Minimart daripada pesaingnya. Memberikan periklanan dan promosi yang menarik guna mempengaruhi pembelian konsumen. Untuk atmosfer dalam gerai diharapkan
Minimart di Desa Ubud Kabupaten Gianyar Bali dapat memberikan ruang gerak yang lebih luas untuk pengunjung dan fasilitas AC bisa lebih dingin karena saat banyak pengunjung fasillitas AC menjadi tidak terasa dingin. Hal ini dimaksudkan agar walaupun dalam keadaan yang ramai konsumen tetap merasa nyaman dalam berbelanja. Penerapan service yang maksimal dalam pelayanan, kemudahan pembayaran sehingga menarik unplaning purchase dicisionsdi Minimart di Desa Ubud Kabupaten Gianyar Bali. 


\section{DAFTAR PUSTAKA}

Abdul Rokim, Muh., Nawazirul Lubis, Andi Wijayant. 2013. Pengaruh Harga, Bauran Produk, dan Kualitas Pelayanan Terhadap Keputusan Pembelian di Pasaraya Sri Ratu Semarang. DiponegoroJournal of Social and Politic. 1(9): h: 1-12

Aisyah Permata Sari.2016. Pengaruh Persepsi Konsumen pada Promosi Penjualan Terhadap Kecenderungan Perilaku Pembelian tidak Terencana.Skripsi Manajemen Fakultas Ekonomi Universitas Sanata Dharma Yogyakarta

Arikunto, Suharsimi. 2013. Prosedur Penelitian Suatu Pendekatan Praktik. Rineka Cipta, Jakarta

Erina Setyani. 2015. Pengaruh Marketing Mix Terhadap Keputusan Pembelian Konsumen di Toko Alat Tulis Hadi Sutrisno Putra 2 Lampung. Jurnal Ekonomi dan Kewirausahaan. 1(3): h: 18-37

Ghozali, Imam, 2011. Aplikasi Analisis Multivariate Dengan Program SPSS. Edisi Kedua.Semarang : Bagian Penerbit Universitas Diponogoro

Hendro Eko Yulianto, Edy Yulianto, Wilopo. 2013. Pengaruh Retail Marketing Mix Terhadap Keputusan Pembelian Tidak Terencana Pada Pusat Perbelanjaan (Survei Pada Konsumen Matahari Department Store Cabang Matos).JurnalAdministrasi Bisnis. 1(2): h: 186-194
Husein, Umar. 2011. Metode Penelitian Untuk Skripsi dan Tesis Bisnis.Edisi 11. Jakarta: PT Raja Grafindo Persada

Kamus Bahasa Indonesia. 2008. Jakarta, Balai Pustaka

Kotler Philip. 2012. Manajemen Pemasaran. Penerjemah. Jakarta: PT. Indeks

Kotler, Philip andG. Armstrong. 2012. Principles of Marketing. 14th $e d$. New Jersey: Prentice Hall

Kotler, Philip dan Keller K. 2012.Manajemen Pemasaran. Jilid 1.Edisi ke 13. Diterjemahkan oleh Bob Sabran, Jakarta: Erlangga

Michael Loekito, Christianto Irawan, Agustinus Nugroho, Endo Wijaya Kartika. 2016. Analisis Pengaruh Marketing Mix 7P Terhadap Keputusan Pembelian Konsumen di Coffee Shop and Tea House Surabaya. .Jurnal Ekonomi dan Kewirausahaan. 1(3): h: 1-15

Oei Pricilia Jeanette. 2015. Pengaruh Marketing Mix Terhadap Keputusan Pembelian Konsumen di Libreria Eatery. Jurnal Manajemen dan Bisnis. 3(4): h: 444-458

Ongky Martha Dwiyananda. 2015. Pengaruh Produk, Harga, Tempat, Promosi Ritel Modern Terhadap Keberlangsungan Usaha Ritel Tradisional di Gresik.Jurnal Manajemen dan Bisnis. 2(9): h: 759-771

Priska Devina, Fransisca Andreani. 2016. Pengaruh Marketing Mix Terhadap Keputusan Pembelian di Susan Spa dan Resort Bandungan. Jurnal 
Teknik Elektro. 6(1): h: 108 120

Rafinko Anggriawan. 2017. Pengaruh Bauran Pemasaran pada Keputusan Pembelian Produk Tupperware di Bandar Lampung.Jurnal Ekonomi dan Kewirausahaan. 3(12): h: 718737
Santoso, Singgih. 2006. Buku Latihan SPSS Statistik Parametrik.Jakarta : Elex Media Komputindo

Schiffman, Kanuk, \& Lazar. 2017. Consumer Behaviour $7^{\text {th }}$ Edition. 
Jurnal Satyagraha, Vol. 02, No. 01, Pebruari - Juli 2019

ISSN :2620-6358

Ni Luh Ketut Ayu Sudha Sucandrawati

Ni Luh Parmi Widiasih 